\title{
Airborne transmission of SARS-CoV-2
}

\author{
Kimberly A. Prather ${ }^{1}$, Linsey C. Marr ${ }^{2}$, Robert T. Schooley ${ }^{3}$, Melissa A. McDiarmid ${ }^{4}$, Mary E. Wilson ${ }^{5,6}$, Donald \\ K. Milton ${ }^{7}$
}

${ }^{1}$ Scripps Institution of Oceanography, University of California San Diego, La Jolla, CA 92037, USA. ${ }^{2}$ Civil and Environmental Engineering, Virginia Tech, Blacksburg, VA 24061, USA. ${ }^{3}$ Department of Medicine, University of California San Diego, La Jolla, CA 92093, USA. ${ }^{4}$ Division of Occupational \& Environmental Medicine, University of Maryland School of Medicine, Baltimore, MD 21201, USA. ${ }^{5}$ School of Medicine, University of California, San Francisco, CA 94143, USA. ${ }^{6} \mathrm{Harvard}$ T.H. Chan School of Public Health, Boston, MA 02115, USA. IInstitute for Applied Environmental Health, University of Maryland, College Park, MD 20742, USA.

*Corresponding author. Email: kprather@ucsd.edu

There is overwhelming evidence that inhalation of severe acute respiratory syndrome coronavirus 2 (SARS-CoV-2) represents a major transmission route for coronavirus disease 2019 (COVID-19). There is an urgent need to harmonize discussions about modes of virus transmission across disciplines to ensure the most effective control strategies and provide clear and consistent guidance to the public. To do so, we must clarify the terminology to distinguish between aerosols and droplets using a size threshold of $100 \mu \mathrm{m}$, not the historical $5 \mu \mathrm{m}$ (1). This size more effectively separates their aerodynamic behavior, ability to be inhaled, and efficacy of interventions.

Viruses in droplets (larger than $100 \mu \mathrm{m}$ ) typically fall to the ground in seconds within $2 \mathrm{~m}$ of the source and can be sprayed like tiny cannonballs onto nearby individuals. Because of their limited travel range, physical distancing reduces exposure to these droplets. Viruses in aerosols (smaller than $100 \mu \mathrm{m}$ ) can remain suspended in air for many seconds to hours, like smoke, and be inhaled. They are highly concentrated near an infected person, so they can infect people most easily in close proximity. But aerosols containing infectious virus (2) can also travel more than $2 \mathrm{~m}$ and accumulate in poorly ventilated indoor air, leading to superspreading events (3).

Individuals with COVID-19, many of whom have no symptoms, release thousands of virus-laden aerosols and far fewer droplets when breathing and talking (4-6). Thus, one is far more likely to inhale aerosols than be sprayed by a droplet (7), and so the balance of attention must be shifted to protecting against airborne transmission. In addition to existing mandates of mask-wearing, social distancing, and hygiene efforts, we urge public health officials to add clear guidance about the importance of moving activities outdoors, improving indoor air using ventilation and filtration, and improving protection for high-risk workers (8).

\section{REFERENCES AND NOTES}

1. National Academies of Science, Engineering, and Medicine, "Video 31-CQ1 reflection and syntheses: Identifying opportunities and gaps on the path ahead by Kim Prather" (Airborne Transmission of SARS-CoV-2: A Virtual Workshop, 26 to 27 August 2020); www.nationalacademies.org/event/08-26-2020/airbornetransmission-of-sars-cov-2-a-virtual-workshop.

2. J. A. Lednicky et al., Int. J. Infect. Dis., 10.1016/j.ijid.2020.09.025 (2020).
3. S. L. Miller et al., Indoor Air, 10.1111/ina.12751 (2020).

4. K. A. Prather, C. C. Wang, R. T. Schooley, Science 368, 1422 (2020).

5. V. Stadnytskyi, C. E. Bax, A. Bax, P. Anfinrud, Proc. Natl. Acad. Sci. U.S.A. 117, 11875 (2020).

6. J. Ma et al., Clin. Infect. Dis., 10.1093/cid/ciaa1283 (2020).

7. W. Chenet al. Build. Environ. 176, 106859 (2020).

8. L. Morawskaet al., Environ. Int. 142, 105832 (2020).

\section{COMPETING INTERESTS}

K.A.P. is Director of the National Science Foundation Center for Aerosol Impacts on Chemistry of the Environment. L.C.M. is a member of the Science Advisory Board and holds stock options for Phylagen and is a paid reviewer for the Alfred P. Sloan Foundation. R.T.S. is a member of the Gilead Sciences Scientific Advisory Board and chairs Data Safety and Monitoring Boards for VIR, Gilead, and Merck. Honoraria for these activities are paid to the Regents of the University of California. R.T.S. has served as a scientific consultant to Pfizer and to AbbVie. M.A.M. is the (unpaid) Chair of the National Academy of Medicine Committee on Personal Protective Equipment for Workplace Safety and Health.

Published online 5 October 2020

10.1126/science.abf0521 